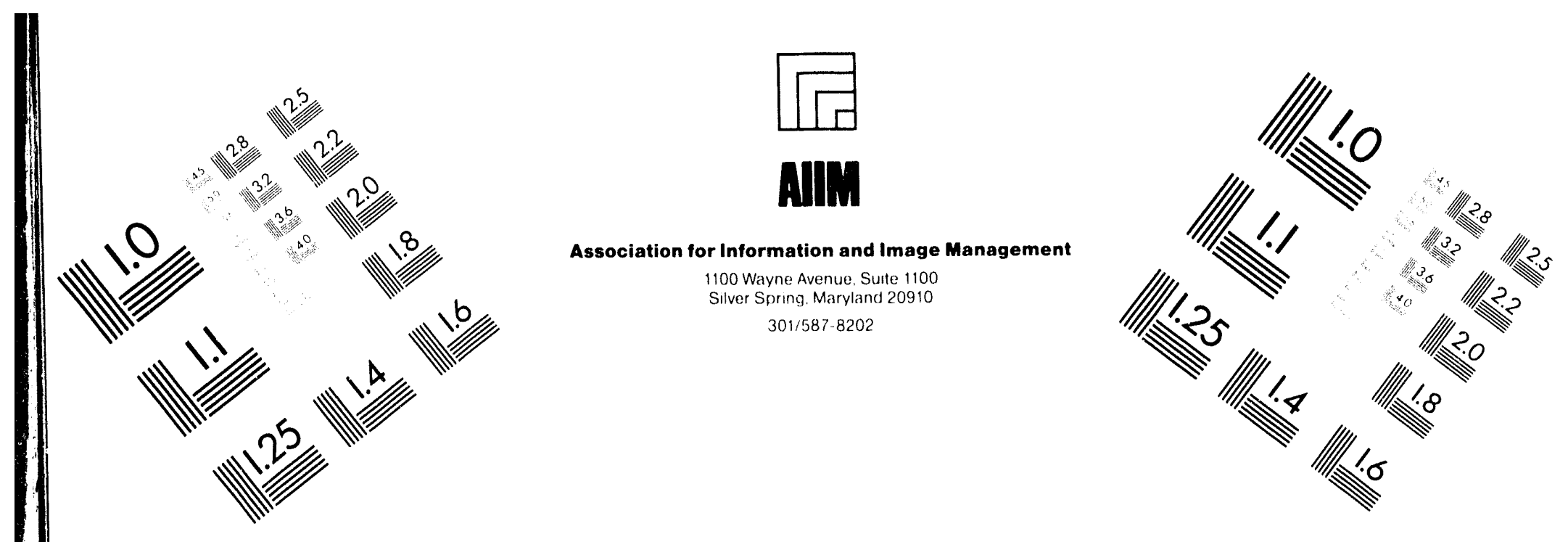

Centimeter

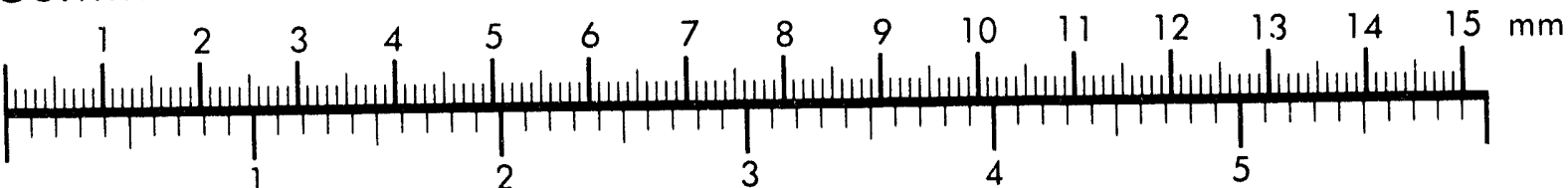
Inches
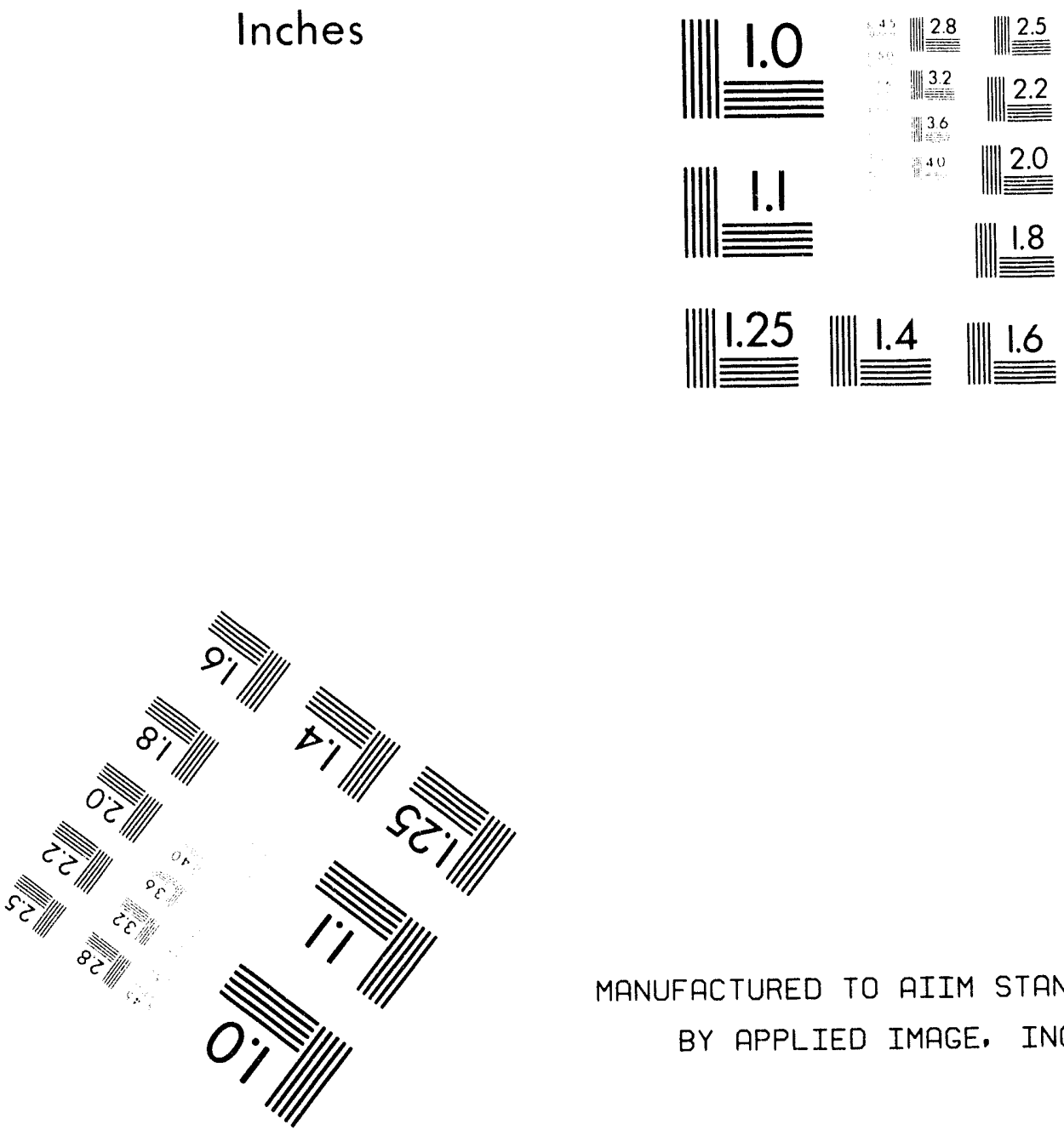

MANUFACTURED TO AIIM STANDARDS BY APPLIED IMAGE. INC.

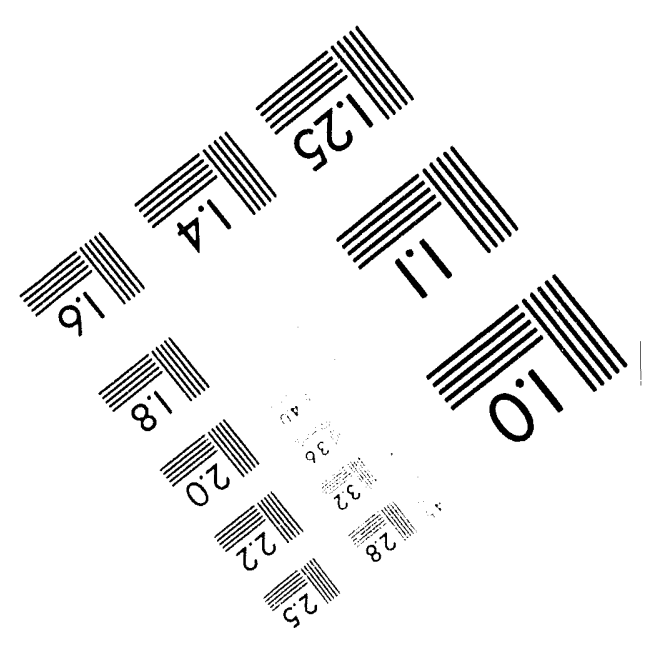



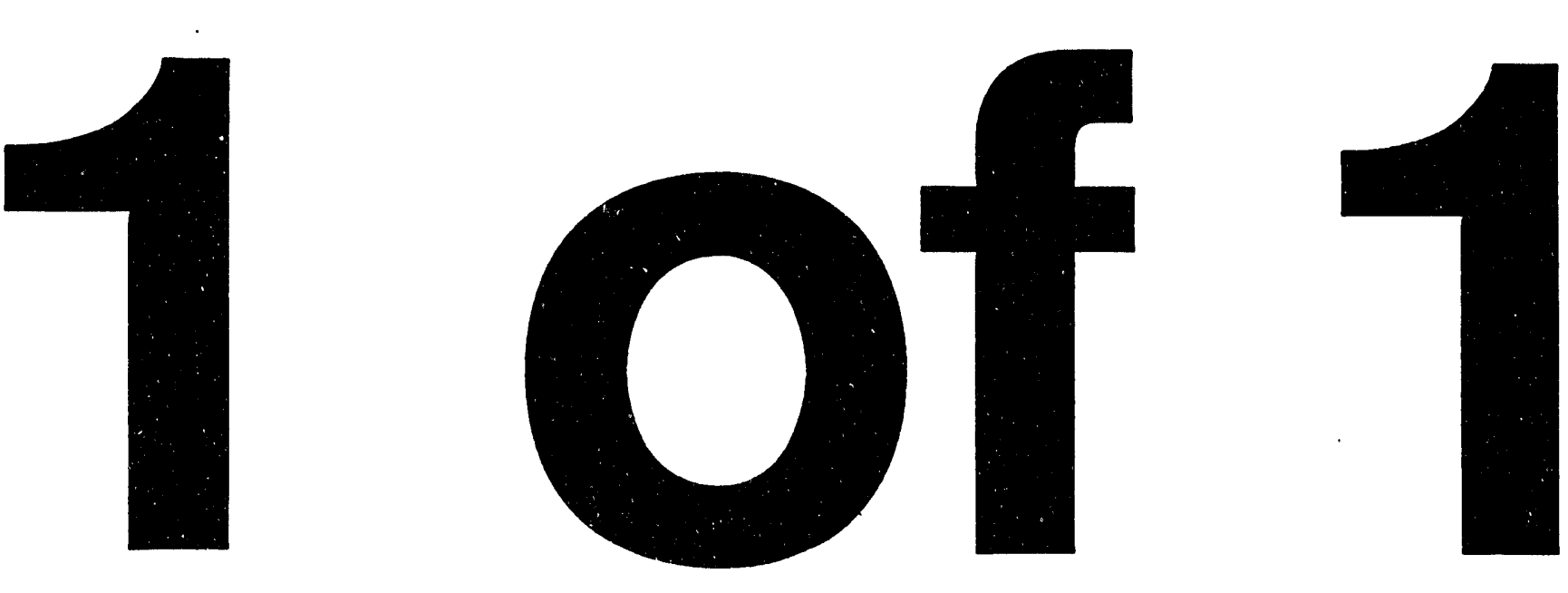
$\varepsilon 60 \varsigma-9 L S$ (S19)

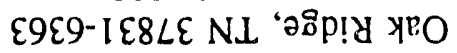
sZ09 '8plg ' $800 Z$ xog 0 'd

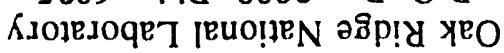

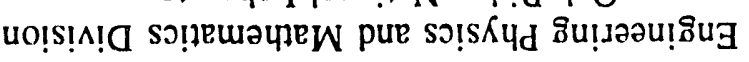

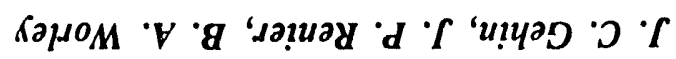

*ADYROS NOYLIBN QBDNVAGV BHL УOA NDISAC DNICVOT TARA MGN V 


\title{
A NEW FUEL LOADING DESIGN FOR THE ADVANCED NEUTRON SOURCE
}

\author{
J. C. Gehin \\ J. P. Renier \\ B. A. Worley \\ Oak Ridge National Laboratory, P.O. Box 2008, Oak Ridge, Tennessee, 37831-6363, USA, \\ (615) 576-5093 \\ KEYWORDS: ANS, Fuel Grading, Fuel Cycle
}

\begin{abstract}
A new fuel loading design has been developed for the Advanced Neutron Source Reactor. In this reactor the combination of a small core volume and high power results in a very high power density. Using a direct optimization procedure the thermal-hydraulic margins for oxide temperature drop. centerline temperature and incipient boiling (and thus critical heat flux) were maximized to increase the limiting thermal power from $298 \mathrm{MW}$ to $346 \mathrm{MW}$ compared to the previous fuel grading, while maintaining the desired peak reflector thermal flux.
\end{abstract}

\section{INTRODUCTION}

The Advanced Neutron Source (ANS) ${ }^{1}$ is a $330 \mathrm{MW}_{\mathrm{f}}$, heavy-water cooled, moderated and reflected reactor currently being designed to meet requirements for materials research. isotope production and neutron research. The primary goal is to obtain peak thermal fluxes in the reflector which are greater than $5 \times 10^{19} \mathrm{~m}^{-2} \cdot \mathrm{s}^{-1}$. The combination of high power and small core volume $(67.6 \mathrm{~L})$ results in a very high power density. In order to increase the thermal-hydraulic margins by reducing power peaking and flattening the power distribution, the fuel is graded within each fuel plate. Previous fuel gradings have led to a substantial improvement in thermal-hydraulic conditions over those of a uniform grading. A more refined fuel grading has been obtained which leads to a much larger increase in operating margins.

Fig. 1 shows a diagram of the two elements in the ANS reactor core. The core consists of two annular fuel elements composed of involute-shaped fuel plates. A cross-section of a fuel plate is shown in Fig. 2. Each fuel plate has a thickness of $1.27 \mathrm{~mm}$ and consists of a fuel meat region of $\mathrm{U}_{3} \mathrm{Si}_{2}-\mathrm{Al}$ and an aluminum filler region $(0.762 \mathrm{~mm}$ in thickness) between aluminum cladding $(0.254 \mathrm{~mm}$ in thickness $)$. The individual plates are separated by a $1.27 \mathrm{~mm}$ coolant channel. The fuel grading procedure consists of finding the two-dimensional fuel meat shape which results in the largest thermal margins. The fuel elements and plates are similar to those currently in use at the High-Flux Isotope Reactor (HFIR) ${ }^{2}$ with the exception that because of its lower power density and light water cooling, only a one-dimensional grading is required. 


\section{METHODS}

The goal in obtaining a new fuel grading is to maximize important temperature margins. In the ANS reactor the most limiting thermal hydraulic conditions are: (1) avoidance of spallation because of the temperature drop over the oxide layer that forms on the aluminum cladding of the fuel plates: (2) the fuel centerline temperature to avoid fuel melting; (3) the cladding wall temperature to avoid coolant boiling. For the ANS reactor the limits on these quantities are ${ }^{3}$ :

$\begin{array}{ll}\text { Oxide temperature drop } & \leq 119^{\circ} \mathrm{C} \\ \text { Centerline Temperature } & \leq 400^{\circ} \mathrm{C} \\ \text { Incipient Boiling Ratio } & <1\end{array}$

where the incipient boiling ratio is the ratio of the temperature at which incipient hoiling begins to the fuel plate wall temperature. Other thermal hydraulic conditions, such at critical heat flux, are also calculated, but are not as limiting as those discussed above under normal operating conditions even with required increased confidence levels.

The fuel cycle calculations were performed using a four-group, finite-difference, diffusion-theory model (without modelling the experimental facilities in the retlector) using the VENTURE code system ${ }^{4}$. A previous study ${ }^{5}$ has determined that diffusion theory is sufficiently accurate, in comparison to transport calculations, for most quantities of interest. The power densities from the VENTURE fuel cycle calculations are used as input to the ANSR steady-state core thermal-hydraulics code ${ }^{6}$ for calculation of the temperature margins. The ANS core thermal-hydraulics code allows the inclusion of uncertainties in the calculations.

The nature of the determination of an optimized fuel grading for the ANS is very similar to that of optimizing fuel cycles in LWR's, for which several efficient methods have been developed (see Reference 7, for example). For this study, a direct fuel-cycle optimization approach has been adopted. The algorithm used is as follows:

(1) Perform a VENTURE fuel cycle calculation for a given fuel loading.

(2) Compute the weighted cycle-averaged power distribution.

(3) Adjust the $U^{235}$ loading based on a linear relationship for a given fuel zone:

New zone $U^{235}$ Loading $=$ Previous zone $U^{235}$ Loading $\times \frac{\text { Desired Zone Power }}{\text { Cycle-Averaged Zone Power }}$

(4) The $U^{235}$ loading is checked to ensure that the maximum fuel meat thickness is not exceeded and that the total mass of fuel is preserved.

(5) Repeat (1) through (4) until the fuel loading is converged.

The grading calculations were performed using this algorithm with different weights on the cycleaveraged power to influence the grading. The desired power was chosen to be the ideal temperature-drop power density protile since this was the most limiting condition in the previous fuel grading (reterred to as the $L 7$ grading). This ideal power density profile results in a uniform oxide-temperature drop throughout the core and has a gentle slope which is higher at the bottom of each element. 


\section{RESULTS}

The results for the neutronic and thermal calculations for the new fuel grading (hereafter referred to as the G693 grading) and the L7 grading (the previous fuel grading) are given in this section. The $\mathrm{U}^{235}$ zone atom densities are given in Fig. 3 for the L7 and the G693 gradings. The plateaus in the L7 grading resulted because of a limit on the uranium density of $1.2 \mathrm{~g} / \mathrm{cm}^{3}$. In the new grading this limit was removed, resulting in a required uranium density of $1.4 \mathrm{~g} / \mathrm{cm}^{3}$. Note that these fuel densities are those required without the experimental facilities modelled. The extra fuel required to offset the reflector components is not expected to significantly affect the shape of the grading. The stepped nature of the atom densities occurs because the atom densities are constant within each fuel zone and Fig. 3 shows the atom density at each calculational mesh point. The total fuel loading in each element is not substantially different from the $\mathrm{L} 7$ design and, therefore, the element criticality, an important consideration during refueling, is nearly the same as for the L7 grading.

The power densities at BOC, MOC and EOC for the $\mathrm{L} 7$ and $\mathrm{G} 693$ gradings are presented in Figures 4-6. Again, the jagged nature of the power densities are a result of the constant $U^{235}$ atom densities within each fuel zone. The sloping of the power densities in the axial direction reflects the nature of the ideal power distribution shape. Note that the large peaks which occur in the L7 power densities have been substantially reduced. At EOC, the power densities are high in the upper element for both gradings because of the control rod motion throughout the cycle (the control rod is withdrawn in the upward direction during the fuel cycle). The fuel grading could not compensate for this power shift without causing power peaking problems in the lower element at BOC. The G693 grading has nearly the same reflector peak thermal flux as the L 7 grading.

The maximum incipient boiling ratio, centerline temperature and oxide temperature drop throughout the cycle are shown in Fig. 7 at a nominal thermal power of $303 \mathrm{MW}$ (note that thermal power refers to the amount of power that must be removed from the fuel elements by the coolant; this value corresponds to a total core fission power of $330 \mathrm{MW}$ ). The large reduction in the maximum centerline temperature and oxide temperature drop in G693 is a result of the reduction of the power peaking at BOC. The maximum incipient boiling ratio is also reduced in the G693 grading.

Calculations of the limiting thermal power for the $95 \%$ uncertainty assumptions given in the Conceptual Safety Analysis Report ${ }^{4}$ were performed and are given in Table 1 tor the L7 and G693 gradings. As this table indicates, the $\mathrm{L} 7$ grading is oxide-temperature-drop limited to a thermal power of $298 \mathrm{MW}$ at MOC. The limiting power for the centerline temperature and oxide temperature drop limits have been substantially increased in the G693 grading. The incipient boiling power limit has also been increased but is the limiting condition for G693 and results in a maximum thermal power of 346 MW at EOC, which is well above the normal operating power of $303 \mathrm{MW}$.

\section{SUMMARY AND CONCLUSIONS}

A new fuel grading which substantially increases all temperature margins was obtained for the ANS reactor. The G693 grading raises the maximum operating thermal power from the $\mathrm{L} 7$ grading value of $298 \mathrm{MW}$ to $346 \mathrm{MW}$. In the development of this fuel grading the use of a gray tip on the control rod and the use of burnable absorbers in the filler were not examined, but may be able to improve conditions at EOC. These grading aspects will be addressed in future studies. 


\section{REFERENCES}

1. COLIN D. WEST, "The Advanced Neutron Source: A New Reactor-Based Facility for Neutron Research," Trans. Am. Nucl. Soc., 61, 375, American Nuclear Society (1990).

2. R. D. CHEVERTON and T. M. SIMS, "HFIR Core Nuclear Design," ORNL-4621, Oak Ridge National Laboratory (1971).

3. "The Advanced Neutron Source Conceptual Safety Analysis Report", ORNL/ANS/INT-33/V2, Oak Ridge National Laboratory (1992)

4. D. R. VONDY, T. B. FOWLER and G. W. CUNNINGHAM, "The BOLD-VENTURE Computation System for Nuclear Reactor Core Analysis, Version III," ORNL-5711, Oak Ridge National Laboratory (1981).

5. Y. Y. AZMY and FELIX C. DIFILIPPO, "Comparison of the Diffusion and Transport Calculations for the Advanced Neutron Source Reactor," Proc. 1988 Intl. Reactor Physics Conference, Jackson Hole, WY, September 18-21, 1988, American Nuclear Society (1988).

6. T. E. COLE, L. F. PARSLY and W. E. THOMAS, "Revisions to HFIR Fuel Element Steady State Heat Transfer Analysis Code," ORNL/CF-85/68, Oak Ridge National Laboratory (1986)

7. D. J. KROPACZEK, G. T. PARKS. G. I. MALDONADO and P. J. TURINSKY, "Application of Simulated Annealing to In-Core Nuclear Fuel Management Optimization," Proc. Int. Top. Mtg. Advances in Mathematics, Computations, and Reactor Physics, Pittsburgh. PA, April 28 May 2, 1991, American Nuclear Society (1991).

Table 1. Limiting thermal power (MW) for the L7 and G693 gradings.

\begin{tabular}{cccccccc}
\hline \multirow{2}{*}{$\begin{array}{c}\text { Time } \\
\text { (days) }\end{array}$} & \multicolumn{2}{c}{ Incipient Boiling Limited } & \multicolumn{2}{c}{ Oxide Temp. Dron Limited } & \multicolumn{2}{c}{ Centerline Temp. Limited } \\
\cline { 2 - 3 } & L7 & G693 & L7 & G693 & L7 & G693 \\
\hline 0.0 & 328.1 & 403.7 & -- & -- & -- & - \\
4.25 & 334.9 & 407.8 & 303.0 & 434.1 & 316.2 & 449.6 \\
8.50 & 375.9 & 450.5 & 298.1 & 387.9 & 314.8 & 401.9 \\
12.75 & 428.9 & 421.3 & 310.9 & 393.7 & 338.5 & 421.6 \\
17.00 & 325.1 & 345.9 & 331.3 & 403.1 & 377.0 & 425.7 \\
\hline \hline
\end{tabular}




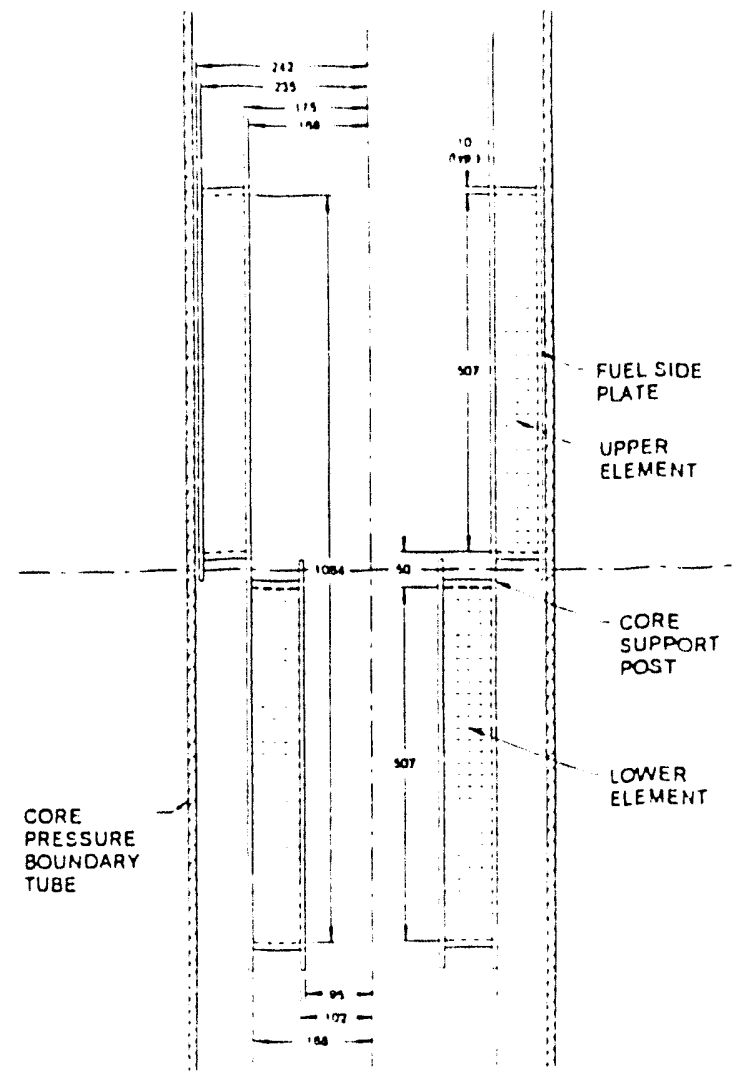

Fig. 1 Diagram of the ANS reactor core.

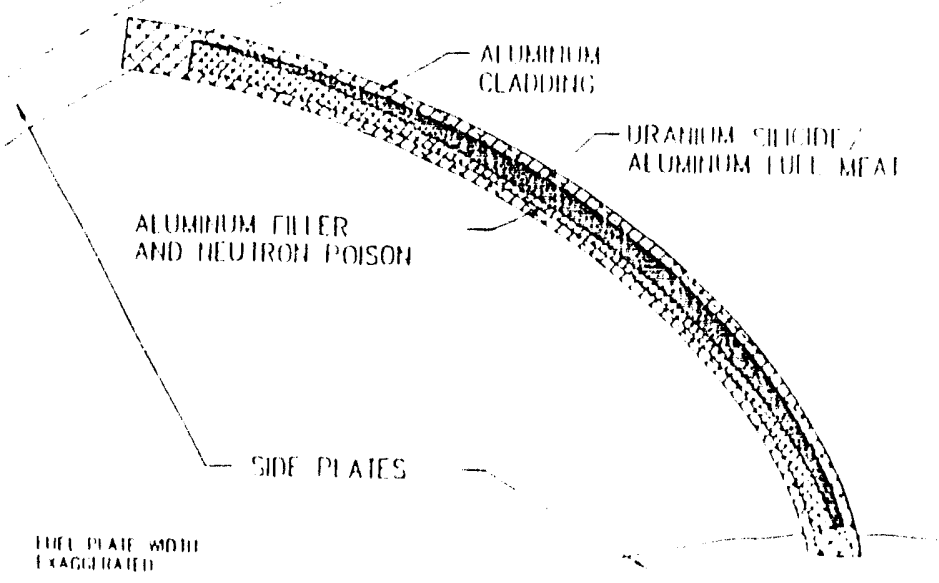

Fig. 2. Diagram of an ANS fuel plate. 

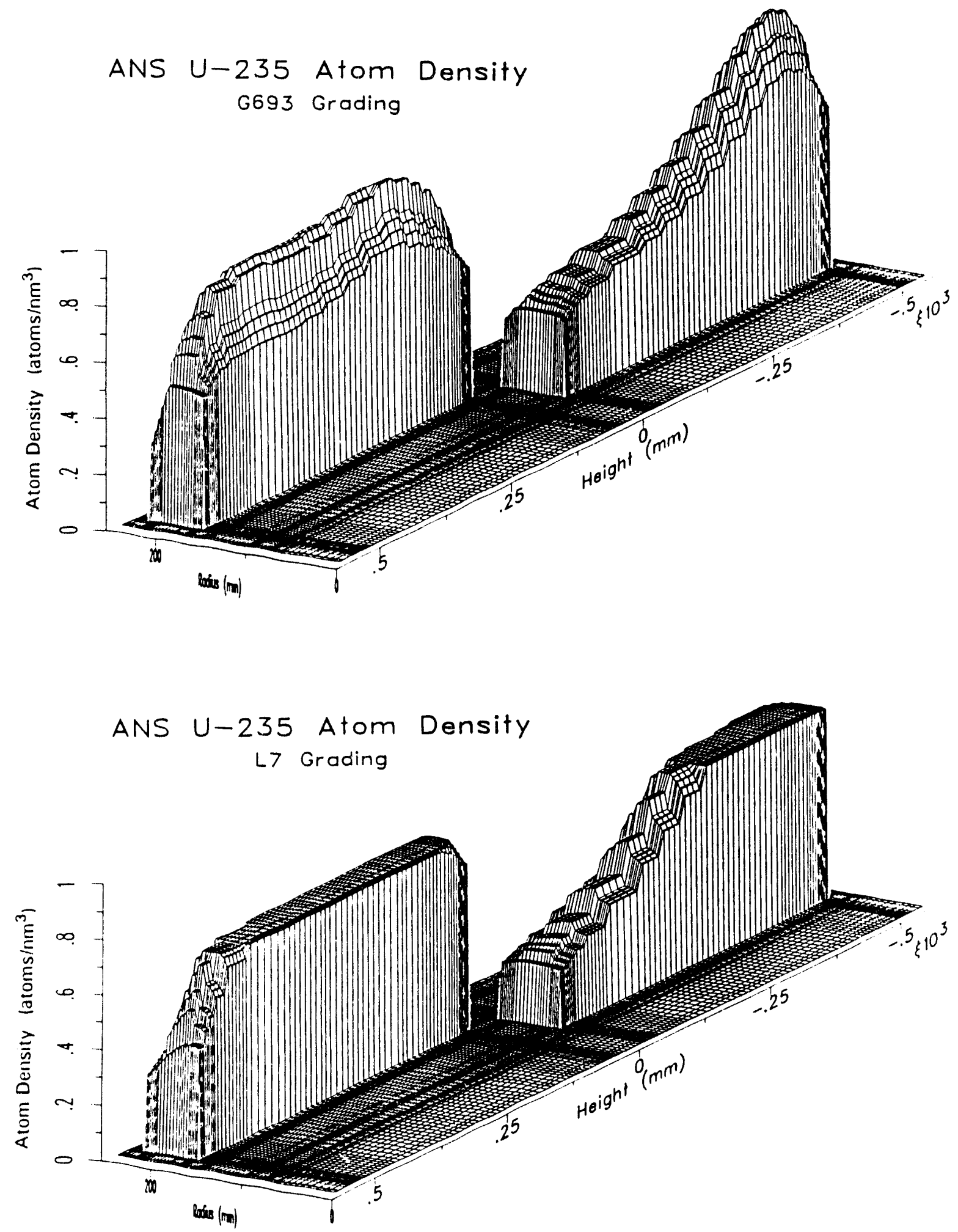

Fig. 3. The $U^{235}$ atom density profiles for the L7 and G693 fuel gradings. 

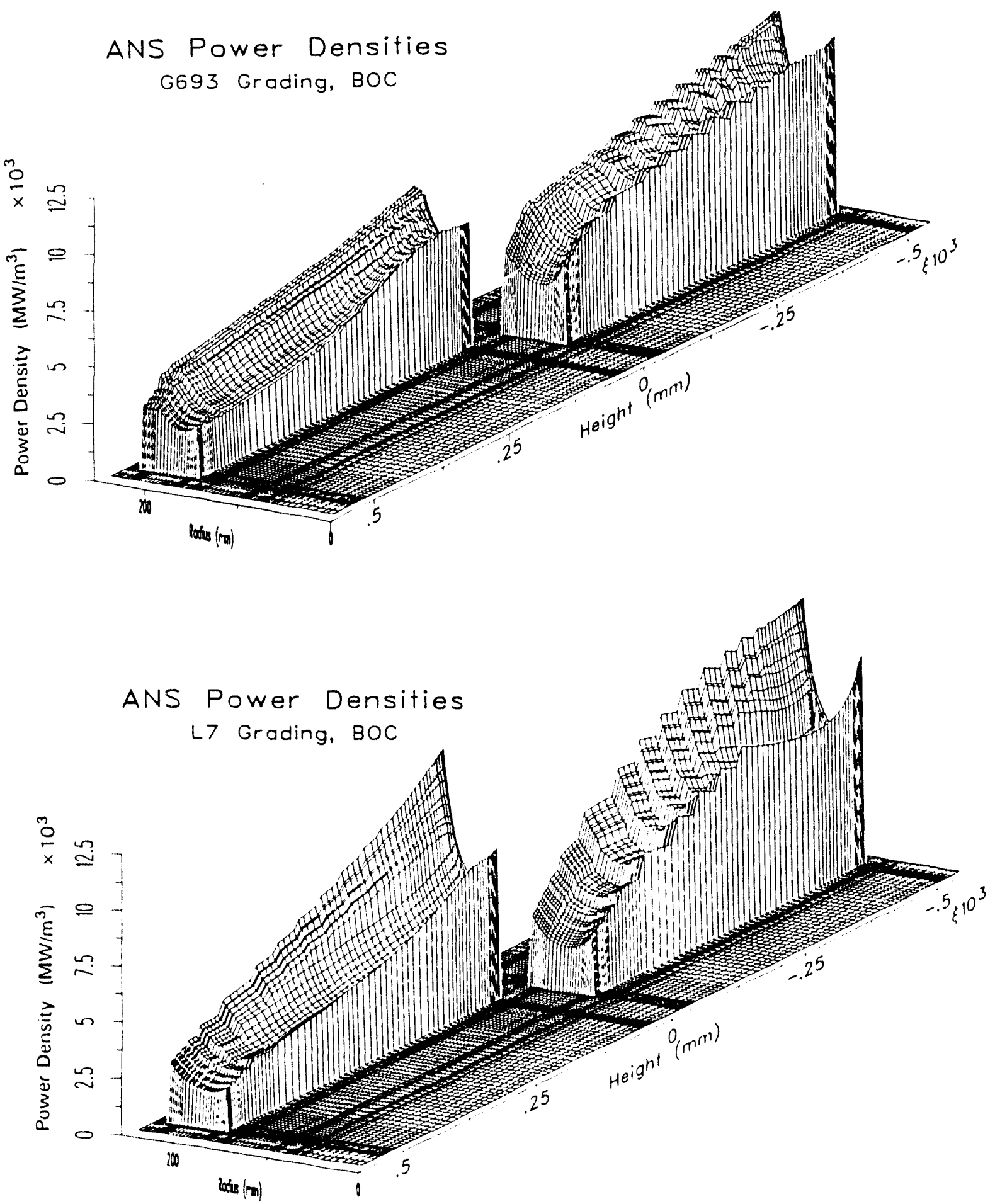

Fig. 4. The power density profiles for the L7 and G693 fuel gradings at BOC. 

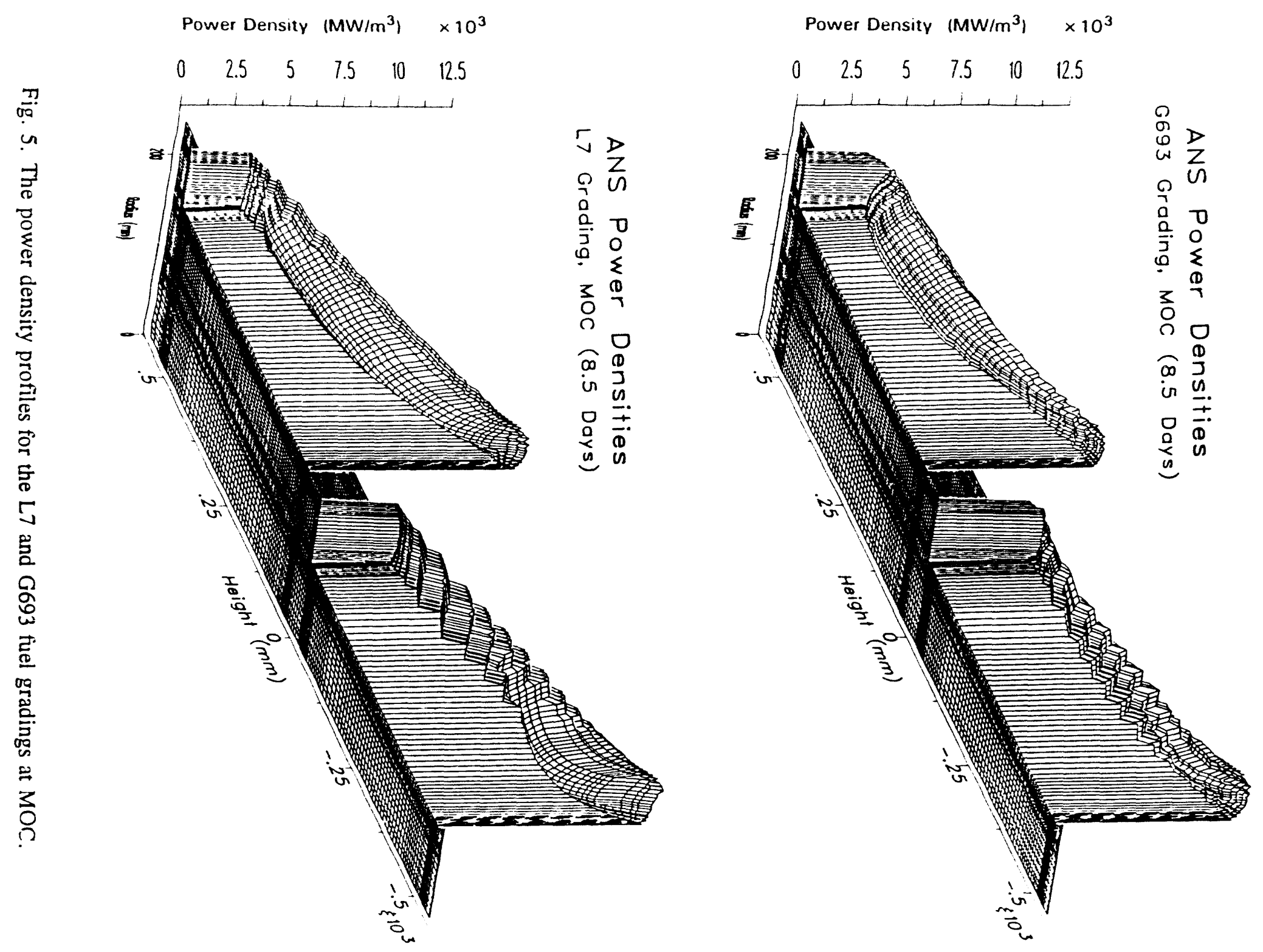

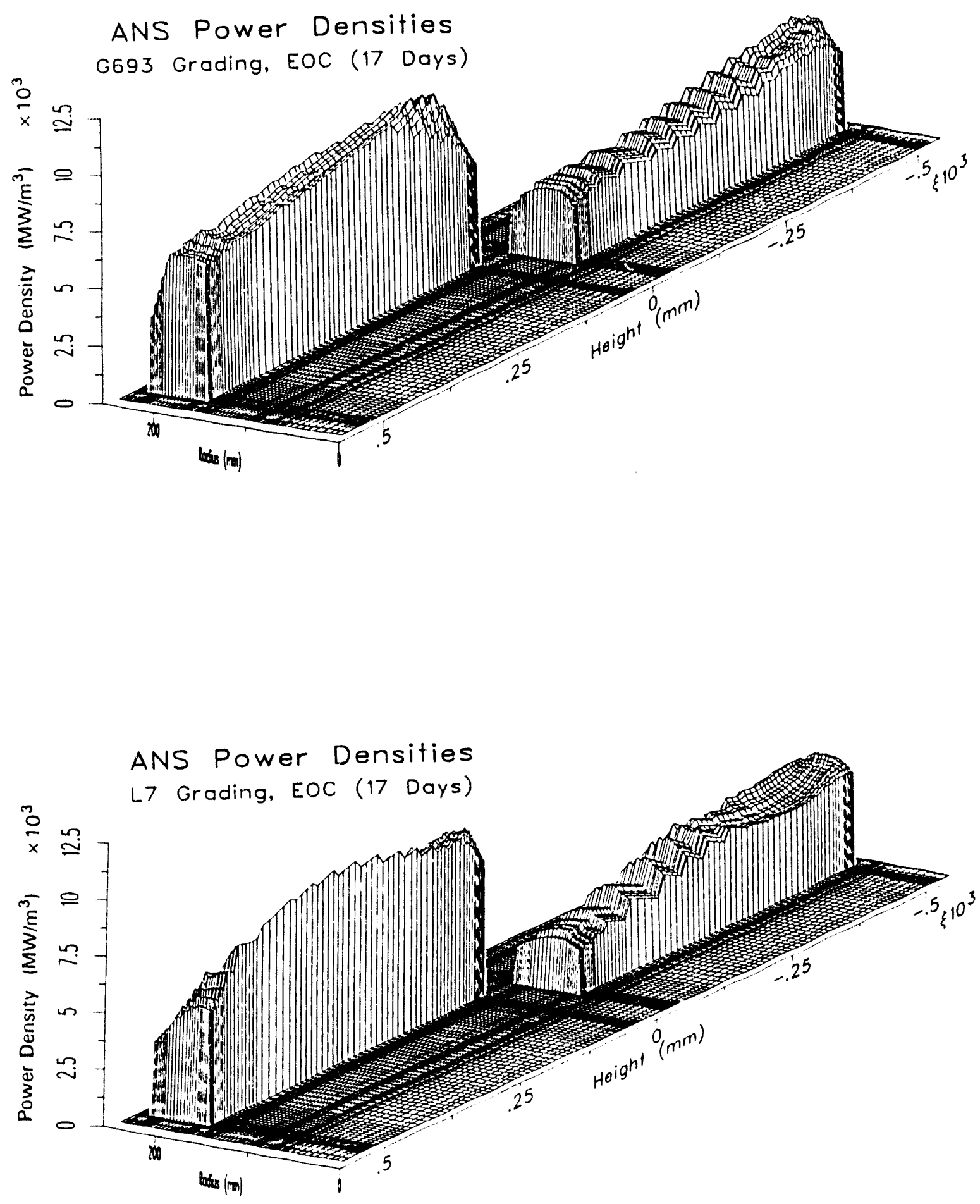

Fig. 6. The power density profiles for the L7 and G693 fuel gradings at EOC. 

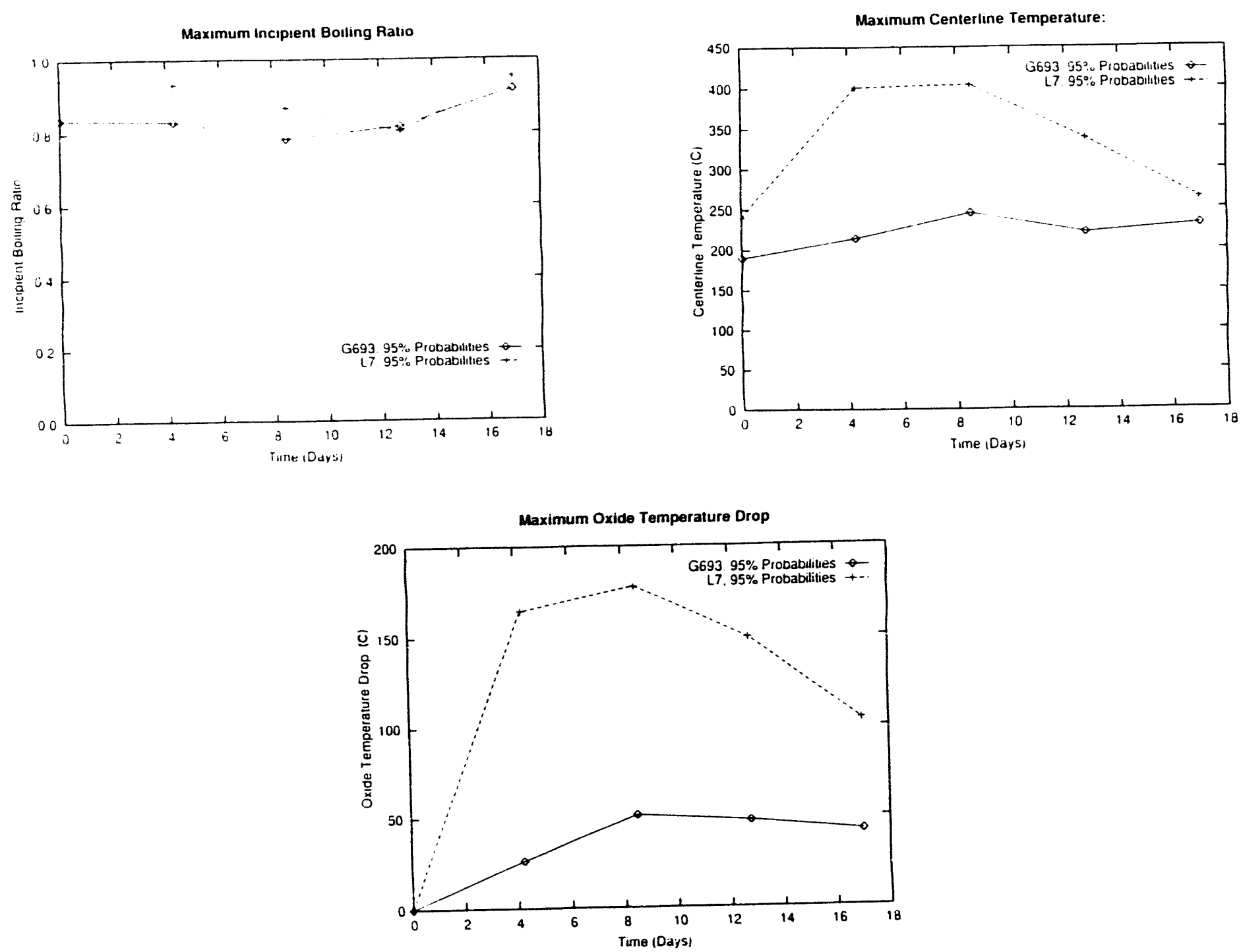

Fig. 7. The incipient boiling ratio, fuel centerline temperature, and oxide temperature drop for the L7 and G693 fuel gradings. 

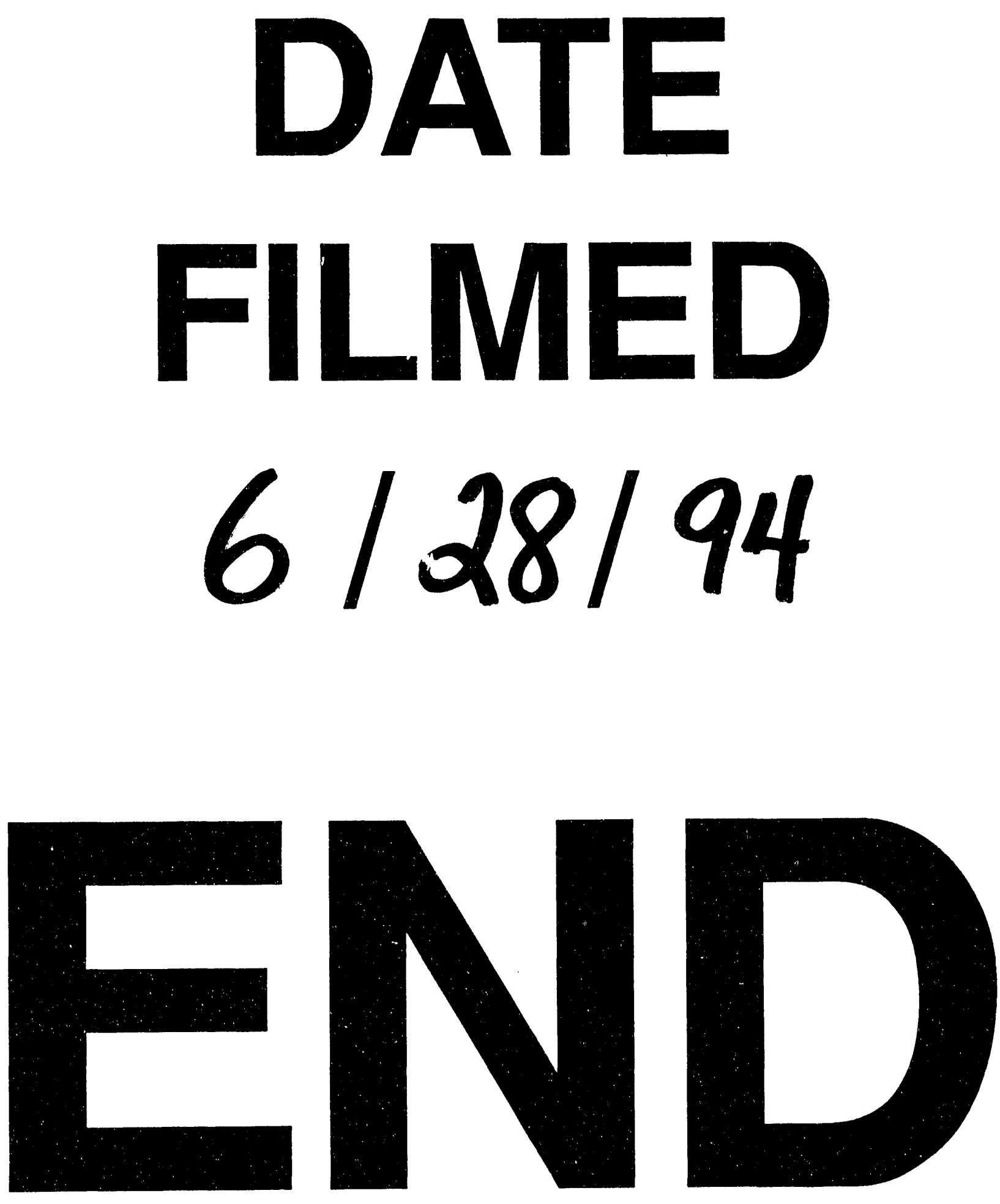
